\title{
In Vitro Characterisation of Pharmacological Effect of Prostacyclin Analogues in Comparison to Phosphodiesterase Inhibitors on Small Human Pulmonary Vessels
}

\author{
Azar Hussain 1*, Robert Bennett1, Zaheer Tahir'1, Ahmed Habib1, Michael Cowen1, \\ Mubarak Chaudhry ${ }^{1}$, Mahmoud Loubani ${ }^{1}$, Alyn Morice ${ }^{2}$
}

${ }^{1}$ Department of Cardiothoracic Surgery, Castle Hill Hospital, Cottingham, UK

${ }^{2}$ Department of Respiratory Medicine, Castle Hill Hospital, Cottingham, UK

Email: *Azar.Hussain@hey.nhs.uk

How to cite this paper: Hussain, A., Bennett, R., Tahir, Z., Habib, A., Cowen, M., Chaudhry, M., Loubani, M. and Morice, A. (2017) In Vitro Characterisation of Pharmacological Effect of Prostacyclin Analogues in Comparison to Phosphodiesterase Inhibitors on Small Human Pulmonary Vessels. World Journal of Cardiovascular Surgery, 7, 131-142.

https://doi.org/10.4236/wjcs.2017.711015

Received: October 22, 2017

Accepted: November 21, 2017

Published: November 24, 2017

Copyright $\odot 2017$ by authors and Scientific Research Publishing Inc. This work is licensed under the Creative Commons Attribution International License (CC BY 4.0).

http://creativecommons.org/licenses/by/4.0/

\begin{abstract}
Background and Aim of Study: The phosphodiesterase inhibitors (Sildenafil and Milrinone), Nitric Oxide donor Sodium Nitroprusside (SNP) and prostacyclin analogs are commonly used pulmonary vasodilators to treat pulmonary hypertension. In the past few years, we have used human pulmonary artery rings in vitro to evaluate pulmonary vascular resistance. The main objective of the current study is to document the pharmacological impact of clinically used prostacyclin analogs on the human pulmonary system in parallel with phosphodiesterase inhibitors and SNP. Methods: The study used human pulmonary artery rings of internal diameter of $2-4 \mathrm{~mm}$ and length of $2 \mathrm{~mm}$. These were extracted from patients with lung resections. These rings were then mounted on a multiwire myograph, and changes in isometric tension were noted. Then, concentration response curves were constructed to Sildenafil (Sd), Milrinone (Mil), Sodium Nitroprusside (SNP), Epoprostenol (Ep), Iloprost (Ip) and Treprostinil (Tp). Results: 52 pulmonary artery rings were used in these experiments. Sildenafil, Milrinone, SNP, Epoprostenol, Iloprost and Treprostinil caused a concentration-dependent vasodilation in small human pulmonary arteries $\left(\mathrm{pEC}_{50}: 5.97 \pm 0.22,5.99 \pm 0.12,7.64 \pm 0.08,7.53 \pm\right.$ $0.14,8.84 \pm 0.15$ and $9.48 \pm 0.13$ respectively, $\mathrm{n}=8$ to 12 ). The efficacy for the same was in the order: $\mathrm{Tp}=\mathrm{Ip}>\mathrm{Ep}>\mathrm{Mil}>\mathrm{SNP}>\mathrm{Sd}$. The potency varied in the order: $\mathrm{Tp}>\mathrm{Ip}>\mathrm{SNP}>\mathrm{Ep}>\mathrm{Mil}>\mathrm{Sd}$. Conclusion: This research showed the efficacy as well as the potency of SNP and phosphodiesterase inhibitors and prostacyclin analogs on the human pulmonary vasculature. Treprostinil and Iloprost exhibited maximum relaxation. However, Sildenafil and SNP showed lesser impact. These effects need to be considered for clinical studies
\end{abstract}


for enhanced patient outcomes.

\section{Keywords}

Pulmonary Artery Rings, Human, Vasodilators, In Vitro, Pulmonary Hypertension Study

\section{Introduction}

Pulmonary hypertension $(\mathrm{PH})$ may be defined as a disorder of the cardio-pulmonary system where pulmonary artery pressure is greater than or equal to $25 \mathrm{~mm}$ mercuric pressure at rest when evaluated via right heart catheterization method [1]. Pulmonary hypertension can be labelled as a life-threatening disorder as it can lead to death if left untreated. The average survival for untreated subjects may be nearly 2 years after disease diagnosis [2]. The pathophysiology of PH involves vasoconstriction that leads to intimal fibrosis, the proliferation of smooth muscle cells and medial hypertrophy. An imbalance in endogenously released vasodilators (NO and prostacyclin) and vasoconstrictors (Endothelin-1) induces vascular remodeling, and therefore $\mathrm{PH}$ is more of a vasoproliferative rather than vasoconstrictive disease [3]. The treatment depends on the disease etiology and the extent of functional disability. The key objective here is to enhance patient outcomes, life quality, and survival rates. Various therapeutic agents, such as prostanoids (Epoprostenol, Treprostinil, Iloprost), phosphodiesterase inhibitors (Sildenafil, Milrinone) and NO, are currently being used to manage $\mathrm{PH}$. Despite recent advances, none of the current treatment regimens is effective in reversing the remodeling of the pulmonary vasculature and reducing mortality. This has led to the recognition that there still exists a need to shortlist some potential therapeutic agents to handle the menace [4].

Vasodilator drugs are commonly used peri-operatively to treat high blood pressure in the pulmonary artery and reduce pulmonary vascular resistance. The effects of commonly used vasodilator agents on pulmonary vascular tone have been extensively investigated clinically. However, there is little work done to compare the direct impact of these drugs on the human pulmonary vasculature. Our group has in recent years developed experience in the use of human pulmonary artery (PA) rings to understand the physiological as well as the pharmacological impact on human pulmonary vessels. The key goal of this research study is to quantify the efficiency as well as the potency of common vasodilators on an isolated human pulmonary artery in contrast with prostacyclin analog variants.

\section{Methods and Materials}

\subsection{Ethical Approval}

These experiments conformed to the Helsinki Declaration of the World Medical 
Association and had rightfully sought ethical approval from the Local Ethics Committee (Ref no: 15/NW/0808-29/09/15) and Local Research and Development Department (Ref no: R1884-09/11/15) approval was obtained. Patients undergoing lung resection have expressed their consent to the use of surplus tissue in writing for scientific research. Hence, patients below 18 years who are not legal for such consent were excluded from the research. Patient demographics remain unknown, as we have no access to patient's details due to ethical approval restriction.

\subsection{Isolation and Mounting of PA Rings}

Pulmonary arteries were collected from subjects undergoing lobectomy for cancer and transferred to the lab in oxygenated $\left(5 \% \mathrm{CO}_{2}: 21 \% \mathrm{O}_{2}\right)$ Krebs-Henseleit solution (containing: (mM) NaCl 118, $\mathrm{KCl} 4.7, \mathrm{MgSO}_{4} 1.2, \mathrm{NaHCO}_{3} 25, \mathrm{KH}_{2} \mathrm{PO}_{4}$ $1.2, \mathrm{CaCl}_{2} 2.4$ and glucose 11). The pulmonary arteries were dissected from disease-less regions in the lung. These were later reduced to $2 \mathrm{~mm}$ long rings after meticulous separation of connective tissues. A total of 64 pulmonary arteries (PA) rings of internal diameter ranging from $2 \mathrm{~mm}$ to $4 \mathrm{~mm}$ were prepared from a total of 18 patients. A multiwire myograph system (DMT 620M) was used to mount PA rings and measure isometric tension [Figure 1, Figure 2]. The myograph system was connected to a computer to continuously measure isometric tension via an amplifier (Power Lab 8/35, AD Instruments) and data acquisition system (Lab Chart Pro Version 8.0).

\subsection{Determination of Agonist Induced Relaxation}

After the successful mounting of PA rings, a resting tension of $1.6 \mathrm{gf}$ was applied that was calculated from earlier experiments and shown to be the optimum resting tension in this model [5]. The vessels were then left to equilibrate with $21 \%$ $\mathrm{O}_{2}: 5 \% \mathrm{CO}_{2}$ at $37^{\circ} \mathrm{C}$ for 1 hour. PA rings were then pre-constricted with 11.21 $\mu \mathrm{M} \mathrm{PGF}_{2 \alpha}\left(\mathrm{EC}_{80}\right)$, calculated earlier from previous experiments [6]. When a stable active tension was achieved, a series of increasing concentration response curves were created for Sildenafil, Milrinone, Sodium Nitroprusside, Epoprostenol, Iloprost and Treprostinil by stepwise increases in agonist concentration in
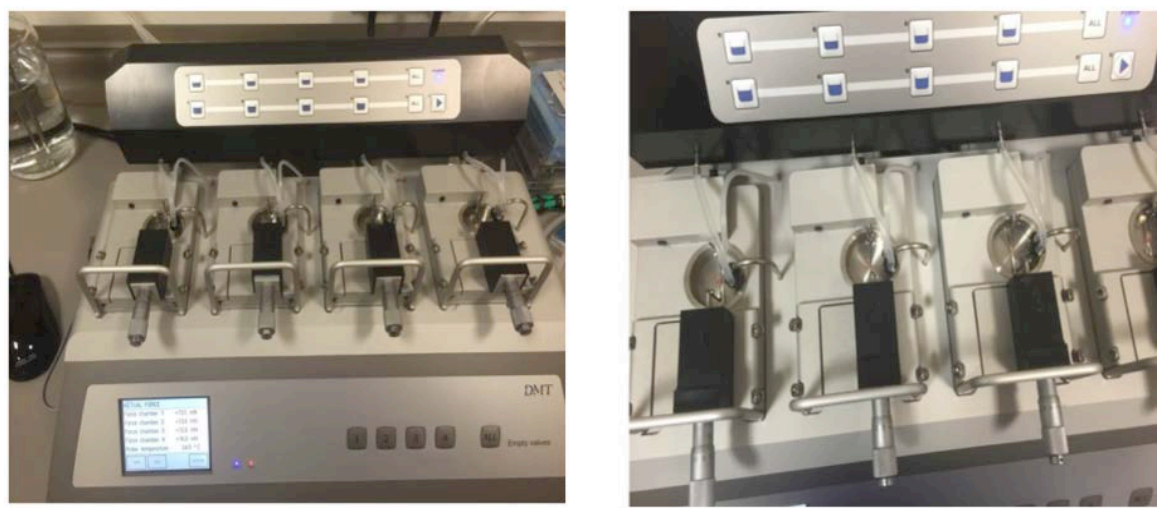

Figure 1. Multiwire myograph system (DMT 620M). 


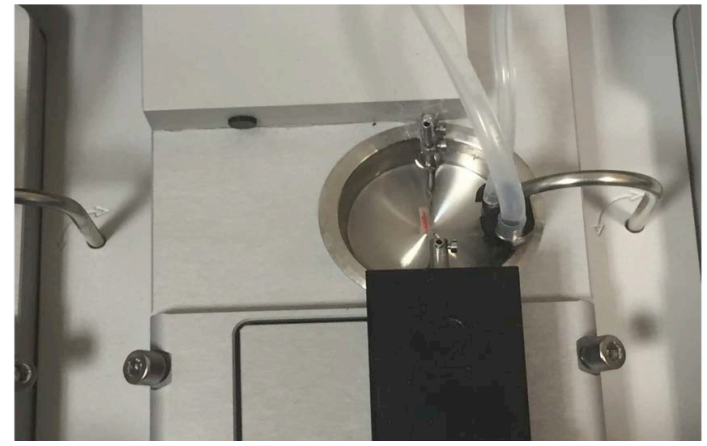

Figure 2. Multiwire myograph unit.

the myograph chamber when a plateau response was generated for the earlier concentration. The active tension was calculated in gram force (gf) as maximum tension at the plateau (gf) - resting tension (gf).

The maximum efficacy $\left(\mathrm{E}_{\max }\right)$ for each agent was determined in gf and expressed as $\mathrm{gf} / \mathrm{mm}$ internal diameter of each vessel (to consider the variability in PA ring diameter). After every experiment, the integrity of the endothelium was rechecked through the addition of $1 \mu \mathrm{M}$ acetylcholine. Potassium chloride $(\mathrm{KCl})$ was used to check the contractility of PA rings. The rings that failed to contract to $\mathrm{KCl}$ were eliminated from the research.

Agonist potency was compared by determining the agonist EC50 concentration (the concentration of agonist needed to generate $50 \%$ of maximum response) which was presented as pEC50 (the negative logarithm of the molar EC50 concentration). The pEC50 was calculated using GraphPad Prism version 7.00 for Windows (GraphPad Software, La Jolla, California, USA. http://www.graphpad.com/guides/prism/6/curve-fitting/index.htm).

\subsection{Statistical Analysis}

Data are expressed as mean \pm SD (standard deviation). " $n$ " refers to the number of individual PA rings used in an experiment. Agonist EC50 were determined using nonlinear regression to fit a standard slope model using the statistical analysis functions of GraphPad Prism version 7.00 for Windows (GraphPad Software, La Jolla, California, USA. More details can be accessed at http://www.graphpad.com/guides/prism/6/curve-fitting/index.htm). The potency $\mathrm{pEC}_{50}$ and efficacy of each drug were compared between groups with ANOVA (one-way analysis of variance) and Bonferroni test with SPSS Statistics 22 software (IBM, Armonk, NY). For experimental studies estimating factors such as concentration-relaxation curves of vasodilator agents were compared via repeated measures ANOVA to record the variation in tone over time. Significance was taken as $\mathrm{p}<0.05$.

\subsection{Materials}

$5 \% \mathrm{CO}_{2} /$ balance air was sourced from BOC Limited. Agents used were Sildenafil (Tocris Bioscience), Milrinone (Stragen, UK), Sodium Nitroprusside (Sig- 
ma-Aldrich), Epoprostenol (GlaxoSmithKline), Iloprost (Tocris Bioscience), Treprostinil (Tocris Bioscience) and Prostaglandin F2a (Tocris Bioscience). Stock solutions of drugs were prepared with the solvent recommended by the supplier. Control responses to solvents were obtained when required. A series of new dilutions were later made for each experiment with the recommended solvent. All other reagents used were from Fisher Scientific unless otherwise specified.

\section{Results}

A total of 64 human pulmonary artery rings (mean internal diameter between 2 and $4 \mathrm{~mm}$ ) were obtained from a total of 18 patients. Since 12 rings failed to contract to $\mathrm{KCl},\left(37.6 \mathrm{mM}\left[\mathrm{EC}_{80}\right]\right.$, calculated earlier [6]), they were eliminated from the study and the remaining 52 rings used. The effects of vasodilator agents on pulmonary artery tone (active tension to $\mathrm{PGF}_{2 \alpha}$ ) are summarised in Table 1 and Figure 3.

Sildenafil, Milrinone, SNP, Epoprostenol, Iloprost and Treprostinil caused concentration-dependent vasodilation in small human pulmonary arteries (pEC50: $5.97 \pm 0.22,5.99 \pm 0.12,7.64 \pm 0.08,7.53 \pm 0.14,8.84 \pm 0.15$ and $9.48 \pm$ 0.13 respectively, $\mathrm{n}=8$ to 12 ). The efficacy order being $\mathrm{Tp}=\mathrm{Ip}>\mathrm{Ep}>\mathrm{Mil}>$ SNP $>$ Sd, and potency in the order: Tp $>$ Ip $>$ SNP $>$ Ep $>$ Mil $>$ Sd.

Repeated results at different doses from each vasodilator agent, when compared with ANOVA and Bonferroni test using SPPS Statistics, show that there were statistical differences in the mean \% vasodilation made over time between vasodilator groups $(\mathrm{p}<0.05)$. The mean $\%$ vasodilation for each vasodilator in ascending order was; Sildenafil: 11.815 (95\% CI 14.12 - 26.75), Milrinone: 15.28 (95\% CI 8.96 - 21.59), Epoprostenol: 20.43 (95\% CI 14.12 - 26.75), SNP: 24.85 (95\% CI 18.54 - 31.16), Iloprost: 30.24 (95\% CI 23.93 - 36.56) and Treprostinil:

Table 1. Summary of number of PA rings (n) and concentration of Sildenafil, Milrinone, SNP, Epoprostenol, Iloprost and Treprostinil used to determine their effect on human pulmonary artery reactivity.

\begin{tabular}{ccccccc}
\hline & Sildenafil & Milrinone & SNP & Epoprostenol & Iloprost & Treprostinil \\
\hline Number of PA rings & 12 & 08 & 08 & 08 & 08 & 08 \\
Number of patients & 04 & 02 & 02 & 03 & 03 & 02 \\
Min concentration & $100 \mathrm{pM}$ & $3000 \mathrm{pM}$ & $100 \mathrm{pM}$ & $100 \mathrm{pM}$ & $10 \mathrm{pM}$ & $1 \mathrm{pM}$ \\
Max Concentration & $100 \mu \mathrm{M}$ & $100 \mu \mathrm{M}$ & $3 \mu \mathrm{M}$ & $3 \mu \mathrm{M}$ & $0.1 \mu \mathrm{M}$ & $0.3 \mu \mathrm{M}$ \\
Min log concentration & $1 \mathrm{E}-10 \mathrm{M}$ & $1 \mathrm{E}-8.5$ & $1 \mathrm{E}-10 \mathrm{M}$ & $1 \mathrm{E}-10 \mathrm{M}$ & $1 \mathrm{E}-11 \mathrm{M}$ & $1 \mathrm{E}-12 \mathrm{M}$ \\
Max log concentration & $1 \mathrm{E}-4.0 \mathrm{M}$ & $1 \mathrm{E}-4.0 \mathrm{M}$ & $1 \mathrm{E}-5.5 \mathrm{M}$ & $1 \mathrm{E}-5.5 \mathrm{M}$ & $1 \mathrm{E}-7 \mathrm{M}$ & $1 \mathrm{E}-6.5 \mathrm{M}$ \\
Diameter $(\mathrm{mm})$ & $2.79 \pm 0.39$ & $2.43 \pm 0.67$ & $2.93 \pm 0.62$ & $3.5 \pm 0.53$ & $2.62 \pm 0.44$ & $3.75 \pm 0.26$ \\
$\mathrm{E}_{\max }(\mathrm{gf})$ & -1.078 & -1.749 & -1.533 & -1.82 & -2.001 & -2.03 \\
$\mathrm{E}_{\max }(\mathrm{gf} / \mathrm{mm})$ & -0.11 & -0.23 & -0.17 & -0.16 & -0.24 & -0.17 \\
$\mathrm{EC}$ & $1.06 \mu \mathrm{M}$ & $1.01 \mu \mathrm{M}$ & $0.022 \mu \mathrm{M}$ & $0.029 \mu \mathrm{M}$ & $0.001 \mu \mathrm{M}$ & $00003 \mu \mathrm{M}$ \\
\hline
\end{tabular}

$\mathrm{E}_{\max }(\mathrm{gf})=$ Maximum $=$ maximum vasodilatory response measured in gf. $\mathrm{E}_{\max }(\mathrm{g} / \mathrm{mm})=$ maximum average response to the vasodilator agent as $\mathrm{g}$ for cenormalized per $\mathrm{mm}$ of average dinternal circumference. $\mathrm{EC}_{50}$ refers to molar concentration of the drug that gives half maximal response. 
Combined Concentration Response Curve $(n=52)$

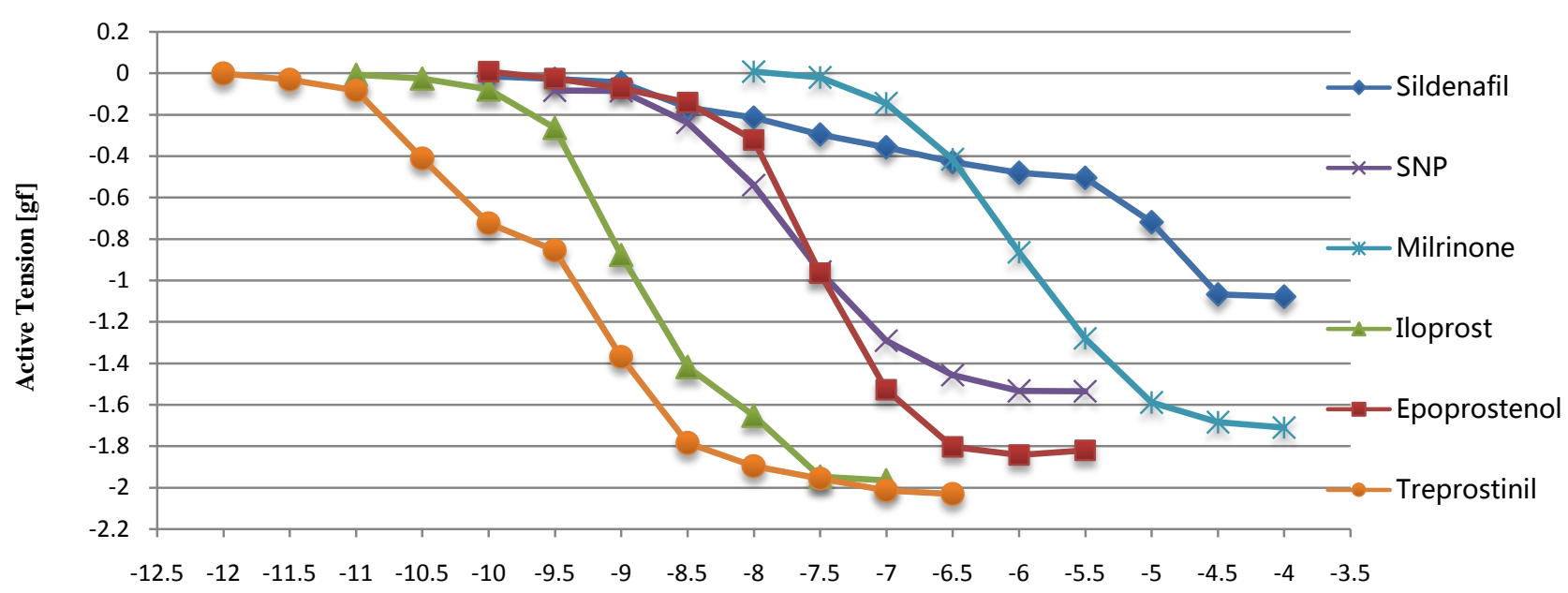

Log Value [M]

Figure 3. Cumulative concentration response curve to Sildenafil $(\mathrm{n}=12)$, Milrinone $(\mathrm{n}=8)$, SNP $(\mathrm{n}=8)$, Epoprostenol $(\mathrm{n}=8)$, Iloprost $(\mathrm{n}=8)$ and Treprostinil $(\mathrm{n}=8)$.

41.74 (95\% CI 35.42 - 48.05). Within-subject analysis of all the vasodilator agents does display an increase in mean $\%$ vasodilation over time $(\mathrm{p}<0.05)$.

$\mathrm{E}_{\max }$ (gf) for Sildenafil, Milrinone, SNP, Epoprostenol, Iloprost and Treprostinil was -1.078 gf, -1.749 gf, -1.533 gf, -1.82 gf, -2.001 gf and -2.03 gf respectively. Another useful indicator for variation in PA rings internal diameter is comparison of the total active force of $2 \mathrm{~mm}$ long artery segment normalised for internal diameter $\left[(\mathrm{g} / \pi \mathrm{D}), \mathrm{g}=\mathrm{E}_{\max }(\mathrm{gf}), \pi=\right.$ mathematical constant which is a measure of ratio of a circle's circumference to its diameter and is approximately 3.14159 and $\mathrm{D}=$ average internal diameter of vessels]. By using this index, the value $\left[\mathrm{E}_{\max }(\mathrm{gf} / \mathrm{mm})\right]$ for Sildenafil, Milrinone, SNP, Epoprostenol, Iloprost and Treprostinil was $-0.11 \mathrm{gf} / \mathrm{mm},-0.23 \mathrm{gf} / \mathrm{mm},-0.17 \mathrm{gf} / \mathrm{mm},-0.16 \mathrm{gf} / \mathrm{mm},-0.24$ $\mathrm{gf} / \mathrm{mm}$, and $-0.17 \mathrm{gf} / \mathrm{mm}$ respectively.

Effect of Sildenafil on the active tension in response to Prostaglandin F2 $\alpha$ :

All vessels vasodilate in response to Sildenafil. Increasing concentrations of $\mathrm{Sd}$ from $100 \mathrm{pM}$ to $100 \mu \mathrm{M}$ were used on $12 \mathrm{PA}$ rings. The EC20, EC50, and $\mathrm{EC}_{80}$ were $37.32 \mathrm{nM}, 1.06 \mu \mathrm{M}$ and $30.33 \mu \mathrm{M}$, respectively. The hill slope was $-0.414 \pm$ 0.089 .

Effect of Milrinone on the active tension in response to Prostaglandin F2 $\alpha$ :

To evaluate the effect of Milrinone on pulmonary vessels, $8 \mathrm{PA}$ rings and concentrations of Milrinone from $3 \mathrm{nM}-100 \mu \mathrm{M}$ were used. As the concentration rose above $10 \mathrm{nM}$, vessels started relaxing, and the maximum response was seen at $30 \mu \mathrm{M}$ The EC20, EC50, and $\mathrm{EC}_{80}$ were $238 \mathrm{nM}, 1.01 \mu \mathrm{M}$ and $4.3 \mu \mathrm{M}$ respectively. The hill slope was $-0.959 \pm 0.234$.

Effect of Sodium Nitroprusside on the active tension in response to Prostaglandin F2a:

$\mathrm{PGF}_{2 \alpha}$ at a concentration of $100 \mathrm{pM}-3 \mu \mathrm{M}$ was used on $8 \mathrm{PA}$ rings to demon- 
strate its vasoconstriction effect. The EC20, EC50 and $\mathrm{EC}_{80}$ were $6.1 \mathrm{nM}, 22.6$ $\mathrm{nM}$ and $83.95 \mathrm{nM}$, respectively. The hill slope was $-1.058 \pm 0.191$.

Effect of Epoprostenol on the active tension in response to Prostaglandin F2 $\alpha$ :

A total of 8 PA rings from 3 patients were studied in this series. Increasing concentrations of Epoprostenol from $100 \mathrm{pM}$ to $3 \mu \mathrm{M}$ were used. Vessels started to dilate as the concentration increased above $300 \mathrm{pM}(\log -9.5 \mathrm{M})$; the maximal relaxation was seen at $1 \mu \mathrm{M}$; after that, the response to Ep diminished. The EC20, EC50 and $\mathrm{EC}_{80}$ were $10.25 \mathrm{nM}, 29.4 \mathrm{nM}$ and $84.56 \mathrm{nM}$, respectively. The hill slope was found to be $-1.314 \pm 0.492$.

Effect of Iloprost on the active tension in response to Prostaglandin F2 $\alpha$ :

To demonstrate the effect of Iloprost on 08 PA rings, a concentration of Ip of $10 \mathrm{pM}-100 \mathrm{nM}$ was used. All vessels were relaxed to Ip with maximal relation recorded at $30 \mathrm{nM}$. The EC20, EC50 and $\mathrm{EC}_{80}$ were $381.91 \mathrm{pM}, 1.43 \mathrm{nM}$ and $5.395 \mathrm{nM}$, respectively. The hill slope was $-1.047 \pm 0.352$.

Effect of Treprostinil on the active tension in response to Prostaglandin F2 $\alpha$ :

Treprostinil at a concentration of 1 pM-300 $\mathrm{nM}$ was used on $8 \mathrm{PA}$ rings to demonstrate its vasodilator effect. The EC20, EC50, and $\mathrm{EC}_{80}$ were $47.457 \mathrm{pM}$, $328 \mathrm{pM}$ and $2.268 \mathrm{nM}$, respectively. The hill slope was $-0.717 \pm 0.142$.

\section{Discussion}

This is the leading research to show the variations in the in vitro effects of clinically used vasodilators on small human pulmonary vessels. Sildenafil, Milrinone, Nitric oxide and prostacyclin analogs are frequently used as pulmonary vasodilators in cardiac surgery patients.

Both Sildenafil and Milrinone are phosphodiesterase enzyme inhibitors while $\mathrm{NO}$ is a guanylatecyclase stimulator [7]. Nitric oxide synthase (NOS) produces NO by catalytic conversion of L-arginine to L-citrulline in the presence of oxygen [8]. Nitric oxide is either generated endogenously in pulmonary vascular endothelial cells or is exogenously administered. It stimulates the synthesis of intracellular guanosine-3',5'-cyclic monophosphate (cGMP) by activating soluble guanylatecyclase (GC) [9]. cGMP activates different protein kinases and through the opening of calcium-gated $\mathrm{K}+$ channels and a reduction in intracellular calcium leads to the relaxation of vascular smooth muscle cells [10].

Several different isoforms of phosphodiesterase enzyme (PDE) especially PDE $1,2,3,5$, and 9 are present in lungs that can inactivate cGMP [11]. Phosphodiesterase inhibitors have been proven to reduce resistance in pulmonary vessels and are now an approved treatment for pulmonary hypertension [12]. Sildenafil is a phosphodiesterase-5 (PDE-5) inhibitor that acts by reducing cGMP breakdown, which results in increased sensitivity of smooth muscle cells in pulmonary vessels to nitric oxide (NO) and subsequently pulmonary vasodilation [13]. Milrinone is an inotropic and vasodilator agent that acts by inhibiting the phosphodiesterase-3 (PDE-3) enzyme. Inhibition of PDE-3 results in higher intracellular cAMP levels that enhance relaxation of the pulmonary vascular bed [14]. 
Milrinone also plays the role of a positive inotropic agent and is proved to be aiding in right heart failure and $\mathrm{PH}$ [15]. Sodium nitroprusside is an inorganic compound that acts by releasing NO. NO stimulates guanylatecyclase in vascular smooth muscle cells to generate cGMP. This augmented cGMP than activates protein kinase $G$ that phosphorylates different proteins and sequentially causes vessel smooth muscle relaxation [16].

Prostacyclin (PGI2) is a 20-carbon prostaglandin member of the eicosanoid family that is produced in smooth muscle and vascular endothelial cells by cyclooxygenase enzymes mediated oxidation of arachidonic acid and acts via the IP receptor ( $G$ protein-coupled prostacyclin receptor) on endothelial cells and platelets [17]. Activation of the prostacyclin receptor produces cAMP via adenylyl cyclase, which in turn inhibits platelet activation and reduces cytosolic calcium levels. Epoprostenol, Treprostinil, and Iloprost are FDA approved prostacyclin analogs to cure pulmonary hypertension. They exert their beneficial effect by promoting direct pulmonary arterial vasodilation and platelet aggregation inhibition, which reduces resistance in the pulmonary vasculature and ventricular afterload and enhances cardiac output [18] [19]. Epoprostenol is a synthetic preparation of prostacyclin that binds to IP receptor and has a short half-life of 6 minutes due to rapid enzymatic hydrolyzation in blood, that necessitates continuous intravenous delivery ideally via placement of a central catheter [20]. Iloprost requires frequent inhalations, 6 - 9 times per day due to a half-life of only 20 - 30 minutes. Treprostinil is relatively stable at room temperature with a half-life of $4 \mathrm{hr}$ and is available in subcutaneous, intravenous and inhalation forms [21].

Prostacyclin analogues (iloprost and treprostinil) can be obtained in the various formulation and differ in their affinities of binding with the prostanoid receptors. Iloprost readily binds to IP, EP1 (EP = Prostaglandin E2 receptor), EP3 and EP4 receptors, [22] [23], whereas treprostinil has a high affinity for IP and EP2 receptors [24] [25]. Prostaglandin F2 acts via FP receptors and has been used in this study as a pre-constrictor. The reason we selected $\mathrm{PGF}_{2 \alpha}$ is that as it proved to be highly efficacious in previous experiments [6] and also activation of other prostanoid receptors by the prostacyclin analogues is not documented in the literature [26].

Several studies have been performed on each class of agent that claim to improve clinical symptoms and pulmonary hemodynamics; however, to date, only the prostacyclin analogs are known to substantially enhance survival in the long-term (5 year survival-55\%) [27]. Prostacyclin synthase is the enzyme responsible for the formation of prostacyclin. It may be deficient in the pulmonary endothelium of some patients with severe $\mathrm{PH}$. This causes excessive vasoconstriction and platelet aggregation [28]. Prostacyclin and its analogs not only decrease pulmonary artery pressure (PAP) and pulmonary vascular resistance (PVR), but also exhibit anti-inflammatory as well as anti-proliferative properties [29] [30]. 
This study confirmed that Treprostinil not only had a significantly greater potency (pEC50 $9.48 \pm 0.13$ ) as compared to other agonists but also reduced pulmonary vessel tone more efficaciously with an $E_{\max }$ value of -2.03 gf. The recorded potency of Iloprost and Treprostinil (pEC50 $8.84 \pm 0.15$ and $9.48 \pm$ 0.13 respectively) in the current study is higher than recorded in animal studies (pEC50 $6.58 \pm 0.08$ for Treprostinil and $5.48 \pm 0.16$ for Iloprost) [31] [32]. Such species differences in the potency of prostacyclin analogs on the pulmonary vasculature are either due to the difference in the distribution or affinity of Ip receptors or dependent on the agent used for preconstruction [33]. Interestingly, prostacyclin analogs were found to be more potent in rat pulmonary arteries pre-constricted with $\mathrm{PGF}_{2 \alpha}$ in comparison to phenylephrine [34]. On the other hand, prostacyclin analogs are known to activate Ip receptors with similar potency in both humans and animals [35] [36]. Overall this study demonstrates a clear differentiation in the pulmonary pharmacology of prostacyclin analogs, phosphodiesterase inhibitors and NO in small human pulmonary arteries.

There are some limitations to our study. First, it's a laboratory-based research that might not reflect the true physiological environment that pulmonary arteries are exposed to. Secondly, the concentration of drugs used to perform these experiments may not correlate with therapeutic doses and the strength of the drug causing maximal relaxation might be beyond the safe therapeutic index for use in humans. Thirdly, we only used $\mathrm{PGF}_{2 a}$ as a pre-constrictor, but as explained earlier the potency of the relaxing agent is also dependent on the pre-constrictor used, so these results need to be verified by using other pre-constrictor agents like endothelin-1 and phenylephrine. Fully blinded randomized control trials are needed to show the potential bench to bed effect of this study.

\section{Conclusion}

The current research is solely an in vitro analysis to show the efficacy as well as potency of clinically used prostacyclin analogs, SNP and phosphodiesterase inhibitors on small human pulmonary vascular reactivity. It is found that Treprostinil and Iloprost lead to maximal relaxation, while Sildenafil and SNP had a lower effect. These effects are critical for clinical aspects as prostacyclin analogs provide better results, which may be instrumental in enhanced patient outcomes.

\section{Conflict of Interest}

The authors declared no potential conflicts of interest with respect to the research, authorship, and/or publication of this article.

\section{References}

[1] Hoeper, M.M., Bogaard, H.J., Condliffe, R., Frantz, R., Khanna, D., Kurzyna, M., et al. (2013) Definitions and Diagnosis of Pulmonary Hypertension. Journal of the American College of Cardiology, 62, D42-D50.

https://doi.org/10.1016/j.jacc.2013.10.032 
[2] Schermuly, R.T., Ghofrani, H.A., Wilkins, M.R. and Grimminger, F. (2011) Mechanisms of Disease: Pulmonary Arterial Hypertension. Nature Reviews Cardiology, 8, 443-455. https://doi.org/10.1038/nrcardio.2011.87

[3] Sulica, R. and Poon, M. (2004) Current Medical Treatment of Pulmonary Arterial Hypertension. Mount Sinai Journal of Medicine, 71, 103-114.

[4] Sutendra, G. and Michelakis, E.D. (2013) Pulmonary Arterial Hypertension: Challenges in Translational Research and a Vision for Change. Science Translational Medicine, 5, 208sr5. https://doi.org/10.1126/scitranslmed.3005428

[5] Hussain, A., Bennett, R.T., Chaudhry, M.A., Qadri, S.S., Cowen, M., Morice, A.H., et al. (2016) Characterization of Optimal Resting Tension in Human Pulmonary Arteries. World Journal of Cardiology, 8, 553-558.

https://doi.org/10.4330/wjc.v8.i9.553

[6] Hussain, A., Bennett, R., Haqzad, Y., Qadri, S., Chaudhry, M., Cowen, M., et al. (2017) The Differential Effects of Systemic Vasoconstrictors on Human Pulmonary Artery Tension. European Journal of Cardio-Thoracic Surgery, 51, 880-886. https://doi.org/10.1093/ejcts/ezw410

[7] Denninger, J.W. and Marletta, M.A. (1999) Guanylate Cyclase and the NO/cGMP Signaling Pathway. Biochimica et Biophysica Acta, 1411, 334-350. https://doi.org/10.1016/S0005-2728(99)00024-9

[8] Knowles, R.G. and Moncada, S. (1994) Nitric Oxide Synthases in Mammals. Biochemical Journal, 298, 249-258. https://doi.org/10.1042/bj2980249

[9] Schmidt, H.H., Lohmann, S.M. and Walter, U. (1993) The Nitric Oxide and cGMP Signal Transduction System: Regulation and Mechanism of Action. Biochimica et Biophysica Acta, 1178, 153-175. https://doi.org/10.1016/0167-4889(93)90006-B

[10] Lincoln, T.M. and Cornwell, T.L. (1993) Intracellular Cyclic GMP Receptor Proteins. FASEB Journal, 7, 328-338.

[11] Beavo, J.A. (1995) Cyclic Nucleotide Phosphodiesterases: Functional Implications of Multiple Isoforms. Physiological Reviews, 75, 725-748.

[12] Wilkins, M.R., Wharton, J., Grimminger, F. and Ghofrani, H.A. (2008) Phosphodiesterase Inhibitors for the Treatment of Pulmonary Hypertension. European Respiratory Journal, 32, 198-209. https://doi.org/10.1183/09031936.00124007

[13] Antoniu, S.A. (2006) Sildenafil for Pulmonary Arterial Hypertension: When Blue Turns into White. Expert Opinion on Pharmacotherapy, 7, 1801-1810. https://doi.org/10.1517/14656566.7.13.1801

[14] Givertz, M.M., Hare, J.M., Loh, E., Gauthier, D.F. and Colucci, W.S. (1996) Effect of Bolus Milrinone on Hemodynamic Variables and Pulmonary Vascular Resistance in Patients with Severe Left Ventricular Dysfunction: A Rapid Test for Reversibility of Pulmonary Hypertension. Journal of the American College of Cardiology, 28, 1775-1780. https://doi.org/10.1016/S0735-1097(96)00399-3

[15] Price, L.C., Wort, S.J., Finney, S.J., Marino, P.S. and Brett, S.J. (2010) Pulmonary Vascular and Right Ventricular Dysfunction in Adult Critical Care: Current and Emerging Options for Management: A Systematic Literature Review. Critical Care, 14, R169. https://doi.org/10.1186/cc9264

[16] Ignarro, L.J. (1990) Nitric Oxide. A Novel Signal Transduction Mechanism for Transcellular Communication. Hypertension, 16, 477-483.

https://doi.org/10.1161/01.HYP.16.5.477

[17] Geraci, M.W., Gao, B., Shepherd, D.C., Moore, M.D., Westcott, J.Y., Fagan, K.A., et al. (1999) Pulmonary Prostacyclin Synthase Overexpression in Transgenic Mice 
Protects against Development of Hypoxic Pulmonary Hypertension. The Journal of Clinical Investigation, 103, 1509-1515. https://doi.org/10.1172/JCI5911

[18] Ashby, B. (1992) Comparison of Iloprost, Cicaprost and Prostacyclin Effects on Cyclic AMP Metabolism in Intact Platelets. Prostaglandins, 43, 255-261. https://doi.org/10.1016/0090-6980(92)90093-9

[19] Bihari, D., Smithies, M., Gimson, A. and Tinker, J. (1987) The Effects of Vasodilation with Prostacyclin on Oxygen Delivery and Uptake in Critically Ill Patients. The New England Journal of Medicine, 317, 397-403. https://doi.org/10.1056/NEJM198708133170701

[20] Moncada, S. and Vane, J.R. (1981) Prostacyclin and Blood Coagulation. Drugs, 21, 430-437. https://doi.org/10.2165/00003495-198121060-00002

[21] Laliberte, K., Arneson, C., Jeffs, R., Hunt, T. and Wade, M. (2004) Pharmacokinetics and Steady-State Bioequivalence of Treprostinil Sodium (Remodulin ${ }^{\circledR}$ ) Administered by the Intravenous and Subcutaneous Route to Normal Volunteers. Journal of Cardiovascular Pharmacology, 44, 209-214. https://doi.org/10.1097/00005344-200408000-00010

[22] Narumiya, S., Sugimoto, Y. and Ushikubi, F. (1999) Prostanoid Receptors: Structures, Properties, and Functions. Physiological Reviews, 79, 1193-1226.

[23] Lai, Y.J., Pullamsetti, S.S., Dony, E., Weissmann, N., Butrous, G., Banat, G.A., et al. (2008) Role of the Prostanoid EP4 Receptor in Iloprost-Mediated Vasodilatation in Pulmonary Hypertension. American Journal of Respiratory and Critical Care Medicine, 178, 188-196. https://doi.org/10.1164/rccm.200710-1519OC

[24] Clapp, L.H., Finney, P., Turcato, S., Tran, S., Rubin, L.J. and Tinker, A. (2002) Differential Effects of Stable Prostacyclin Analogs on Smooth Muscle Proliferation and Cyclic AMP Generation in Human Pulmonary Artery. American Journal of Respiratory Cell and Molecular Biology, 26, 194-201. https://doi.org/10.1165/ajrcmb.26.2.4695

[25] Aronoff, D.M., Peres, C.M., Serezani, C.H., Ballinger, M.N., Carstens, J.K., Coleman, N., et al. (2007) Synthetic Prostacyclin Analogs Differentially Regulate Macrophage Function via Distinct Analog-Receptor Binding Specificities. The Journal of Immunology, 178, 1628-1634. https://doi.org/10.4049/jimmunol.178.3.1628

[26] Mubarak, K.K. (2010) A Review of Prostaglandin Analogs in the Management of Patients with Pulmonary Arterial Hypertension. Respiratory Medicine, 104, 9-21. https://doi.org/10.1016/j.rmed.2009.07.015

[27] McLaughlin, V.V., Archer, S.L., Badesch, D.B., Barst, R.J., Farber, H.W., Lindner, J.R., et al. (2009) ACCF/AHA 2009 Expert Consensus Document on Pulmonary Hypertension a Report of the American College of Cardiology Foundation Task Force on Expert Consensus Documents and the American Heart Association Developed in Collaboration with the American College of Chest Physicians; American Thoracic Society, Inc.; and the Pulmonary Hypertension Association. Journal of the American College of Cardiology, 53, 1573-1619. https://doi.org/10.1016/j.jacc.2009.01.004

[28] Tuder, R.M., Cool, C.D., Geraci, M.W., Wang, J., Abman, S.H., Wright, L., et al. (1999) Prostacyclin Synthase Expression Is Decreased in Lungs from Patients with Severe Pulmonary Hypertension. American Journal of Respiratory and Critical Care Medicine, 159, 1925-1932. https://doi.org/10.1164/ajrccm.159.6.9804054

[29] Zardi, E.M., Zardi, D.M., Cacciapaglia, F., Dobrina, A., Amoroso, A., Picardi, A., et al. (2005) Endothelial Dysfunction and Activation as an Expression of Disease: Role of Prostacyclin Analogs. International Immunopharmacology, 5, 437-459. 
https://doi.org/10.1016/j.intimp.2004.10.016

[30] Kawabe, J., Ushikubi, F. and Hasebe, N. (2010) Prostacyclin in Vascular Diseases-Recent Insights and Future Perspectives. Circulation Journal, 74, 836-843. https://doi.org/10.1253/circj.CJ-10-0195

[31] Orie, N.N. and Clapp, L.H. (2011) Role of Prostanoid IP and EP Receptors in Mediating Vasorelaxant Responses to PGI2 Analogues in Rat Tail Artery: Evidence for $\mathrm{G}_{\mathrm{i} / \mathrm{o}}$ Modulation via $\mathrm{EP}_{3}$ Receptors. European Journal of Pharmacology, 654, 258-265. https://doi.org/10.1016/j.ejphar.2010.12.005

[32] Morrison, K., Studer, R., Ernst, R., Haag, F., Kauser, K. and Clozel, M. (2012) Differential Effects of Selexipag [Corrected] and Prostacyclin Analogs in Rat Pulmonary Artery. Journal of Pharmacology and Experimental Therapeutics, 343, 547-555. https://doi.org/10.1124/jpet.112.197152

[33] Benyahia, C., Ozen, G., Orie, N., Ledwozyw, A., Louedec, L., Li, F., et al. (2015) Ex Vivo Relaxations of Pulmonary Arteries Induced by Prostacyclin Mimetics Are Highly Dependent of the Precontractile Agents. Prostaglandins \& Other Lipid Mediators, 121, 46-52. https://doi.org/10.1016/j.prostaglandins.2015.09.002

[34] Orie, N.N., Ledwozyw, A., Williams, D.J., Whittle, B.J. and Clapp, L.H. (2013) Differential Actions of the Prostacyclin Analogues Treprostinil and Iloprost and the Selexipag Metabolite, MRE-269 (ACT-333679) in Rat Small Pulmonary Arteries and Veins. Prostaglandins \& Other Lipid Mediators, 106, 1-7. https://doi.org/10.1016/j.prostaglandins.2013.07.003

[35] Whittle, B.J., Silverstein, A.M., Mottola, D.M. and Clapp, L.H. (2012) Binding and Activity of the Prostacyclin Receptor (IP) Agonists, Treprostinil and Iloprost, at Human Prostanoid Receptors: Treprostinil Is a Potent $\mathrm{DP}_{1}$ and $\mathrm{EP}_{2}$ Agonist. Biochemical Pharmacology, 84, 68-75. https://doi.org/10.1016/j.bcp.2012.03.012

[36] Abramovitz, M., Adam, M., Boie, Y., Carrière, M., Denis, D., Godbout, C., et al. (2000) The Utilization of Recombinant Prostanoid Receptors to Determine the Affinities and Selectivities of Prostaglandins and Related Analogs. Biochimica et Biophysica Acta, 1483, 285-293. https://doi.org/10.1016/S1388-1981(99)00164-X 